\title{
New Insights into the Edwards Aquifer-Brackish-Water Simulation, Drought, and the Role of Uncertainty Analysis
}

\section{Key Findings}

- Uncertainty analysis provided insights as to the reliability of the model inputs and model results.

- Brackish water is not expected to move appreciably toward production wells near the transition zone interface if a repeat of drought-of-record conditions (1950-56) occurs.

- The model is reliable for predicting brackish-water movement near production wells.

- The model is not reliable for predicting Bexar County index well J-17 water levels or for predicting flows at Comal and San Marcos Springs.

- Many hydraulic properties of the Edwards aquifer, as well as recharge to the aquifer, remain highly uncertain, even after the model has been calibrated.

The Edwards aquifer is an important water resource in south-central Texas, providing water for residents, businesses, and ecosystems. The aquifer is a highly complex karst system characterized by areas of rapid groundwater flow, faulted and fractured Cretaceous-age rocks, and multiple water-quality zones. Karst aquifer systems include soluble rocks such as limestone and dolomite that can convey tremendous amounts of water through dissolution-enhanced faults and fractures (fig. 1). Recent sustained droughts (2011-15) have heightened concerns about the possible effects of drought on this vital water resource.

The Edwards aquifer consists of three water-quality zones. The freshwater zone of the Edwards aquifer is bounded to the south by a zone of brackish water (transition zone) where the aquifer transitions from fresh to saline water (fig. 2). The saline zone is downdip from the transition zone. There is concern that a recurrence of extreme drought, such as the 7-year drought from 1950 through 1956, could cause the transition zone to move toward (encroach upon) the freshwater zone, causing production wells near the transition zone to pump saltier water. There is also concern of drought effects on spring flows from Comal and San Marcos Springs (fig. 2). These concerns were evaluated through the development of a new numerical model of the Edwards aquifer.

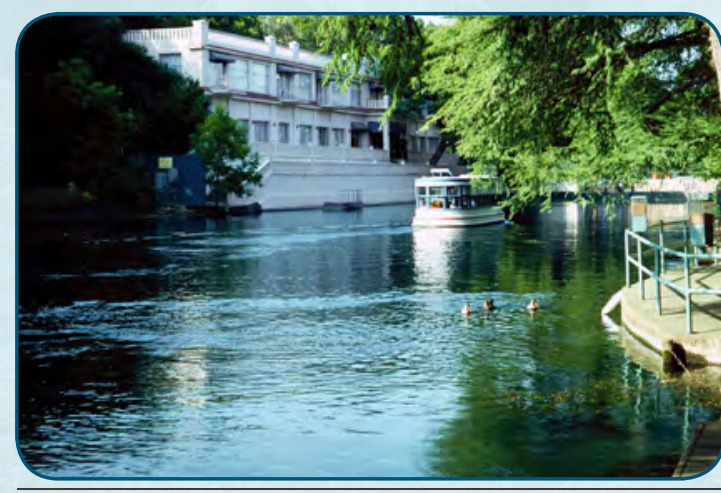

San Marcos Springs. Photograph used with permission from Gregg Eckhardt.

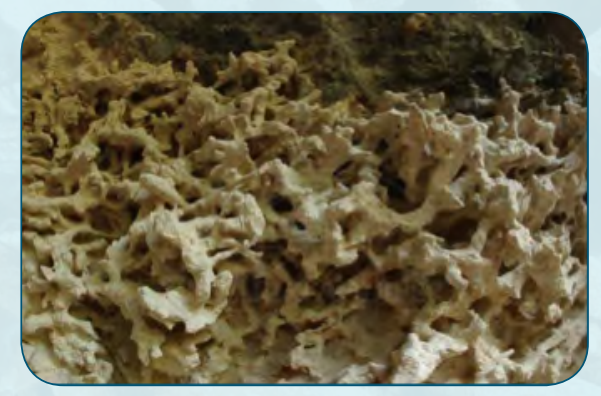

An example of some of the karst rocks of the Edwards aquifer. Photograph used with permission from Gregg Eckhardt.

\section{What was the focus of the model?}

In 2010, the U.S. Geological Survey (USGS), in cooperation with the San Antonio Water System, began a study to simulate brackish-water movement within the Edwards aquifer (more specifically, the potential for brackish-water encroachment into wells near the transition-zone interface) and effects on groundwater heads and on discharge at Comal and San Marcos Springs under drought conditions. A new numerical model was constructed by using SEAWAT, a variable-density groundwater flow and transport code developed by the USGS. SEAWAT allows for more accurate simulation of effects of increased dissolved-solids concentrations (such as those seen in the brackish-water transition zone and saline zone) on density and groundwater flow. Using SEAWAT for this model analysis required the Edwards aquifer to be simulated with eight model layers, many more than were used in previous numerical models of the aquifer (Lindgren and others, 2004; Lindgren, 2006). This increased vertical discretization allows for better representation of the hydrostratigraphy of the aquifer (fig. 1), as well as improved simulation of variable-density groundwater flow. Model results are presented in terms of the upper, middle, and lower parts of the Edwards aquifer (fig. 1). 


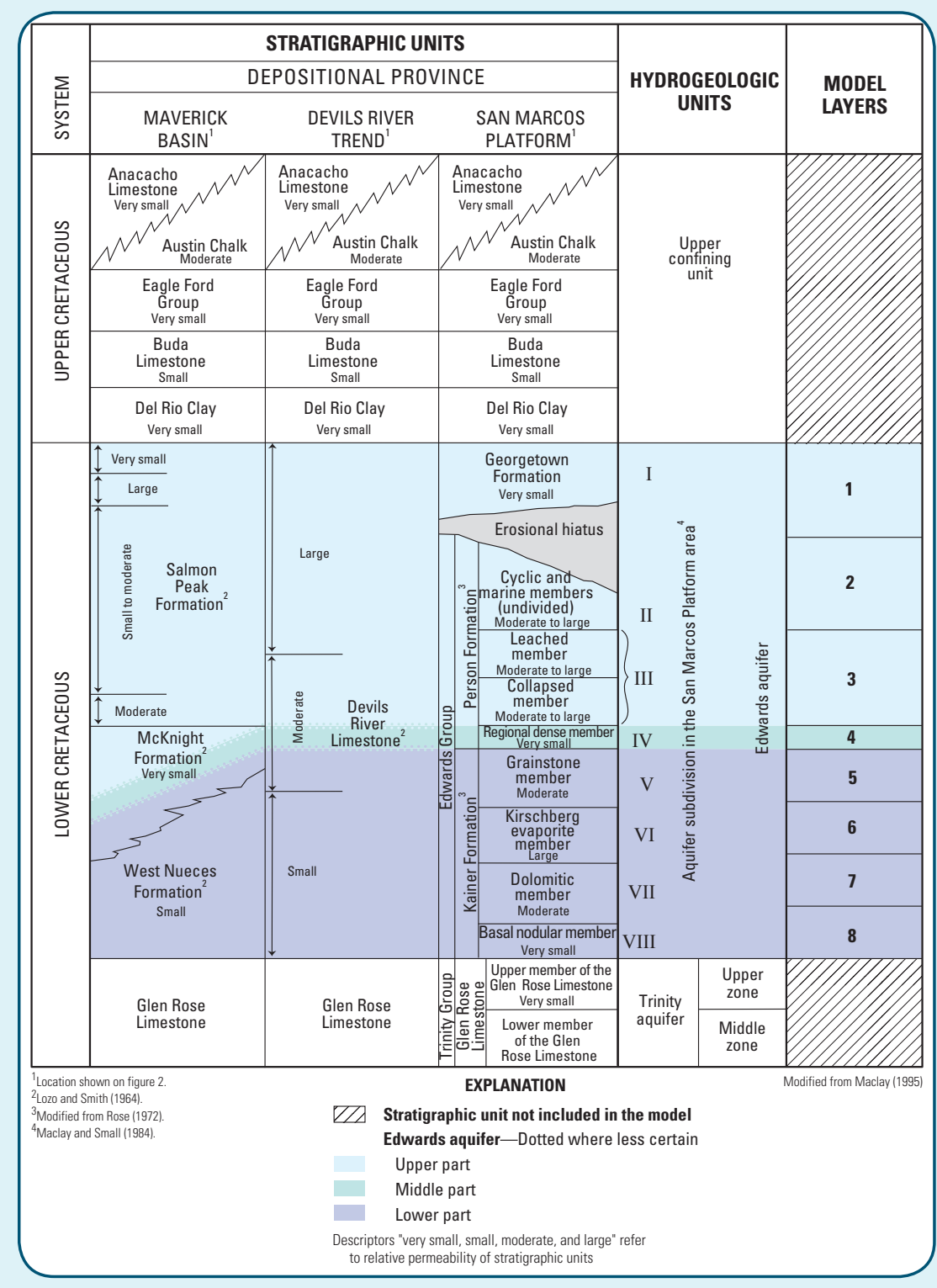

Figure 1. Correlation of Cretaceous stratigraphic units and hydrogeologic units, relative permeability, and model layers in the Edwards aquifer model area, San Antonio region, Texas (modified from Maclay, 1995, fig. 11).
Modeling of the Edwards aquifer was completed in two phases: a calibration (history matching) phase and a predictive phase. History matching is the process of calibrating the model to historical real-world data, such as groundwater levels, spring flows, and dissolved-solids concentrations. Model input parameters, such as hydraulic properties and groundwater recharge, are adjusted during history matching to acquire a sufficient fit of the model output to the real-world data. The model fit was accomplished by using thousands of parameters that adjust aquifer properties and recharge into the aquifer, thousands of real-world data points, and the automated parameter estimation software PEST. Traditional measures of goodness of fit, such as one-to-one plots and correlation coefficients, indicated good agreement between observations and model-simulated equivalents with little or no bias over the range of observed real-world data (fig. 3) for the 1999-2009 time period.

The second phase, the predictive phase, involved modifying the history-matched model to simulate conditions of drought-of-record rainfall during a 7-year drought period (1950-56) combined with recent (1999-2009) pumping amounts. Recent pumping rates are much larger than pumping rates were during the 1950s when far fewer people lived in south-central Texas. The main goals of the predictive phase were to simulate (1) dissolved-solids concentration change at 25 production wells near the transition-zone interface from the beginning of the simulation to the end of the 7-year drought period, (2) the total volume of groundwater flowing from Comal and San Marcos Springs during the 7-year drought period, and (3) the groundwater level at well J-17 at the end of the 7-year drought period. More details about the model development and history matching can be found in Brakefield and others (2015).

\section{What does uncertainty analysis tell us about the Edwards aquifer?}

Uncertainty analysis was applied to the new history-matched model of the Edwards aquifer because the parameters - which control aquifer properties, the spatial distribution of dissolvedsolids concentrations, rates of recharge to the aquifer, and predictions made with the model — all have substantial uncertainty associated with them and because of the inherent complexity of this karst aquifer. Considerable uncertainty exists in the spatial and temporal distribution of dissolved-solids concentrations throughout the Edwards aquifer. Additionally, marked differences exist between the amount of data available for characterizing the freshwater, transition, and saline zones; a relatively large amount of data is available for characterizing the freshwater zone, whereas few data are available for characterizing the transition and saline zones. The relative lack of data for the transition and saline zones contributes to uncertainty in those areas. Because the system is highly complex, few data are available in some areas, and models are known to be non-unique, uncertainty analysis was used to assess what was learned about these parameters through the calibration process.

An example of variable-density flow using SEAWAT version 4. 


\section{Contributing area}

(1) Nueces-West Nueces River Basin

(2) Frio-Dry Frio River Basin

(3) Sabinal River Basin

(4) Area between Sabinal and Medina River Basins (includes Hondo and Seco Creeks)

(5) Medina River Basin

6 Area between Medina River Basin and Cibolo-Dry Comal Creek Basins

(7) Cibolo and Dry Comal Creek Basins

8 Guadalupe River Basin

(9) Blanco River Basin

10 Barton Springs segment contributing area (includes Barton, Williamson, Slaughter, Bear, and Onion Creeks)

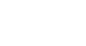

(1)

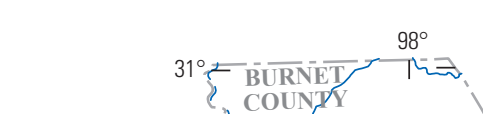

ry Comal Creek Basins

-

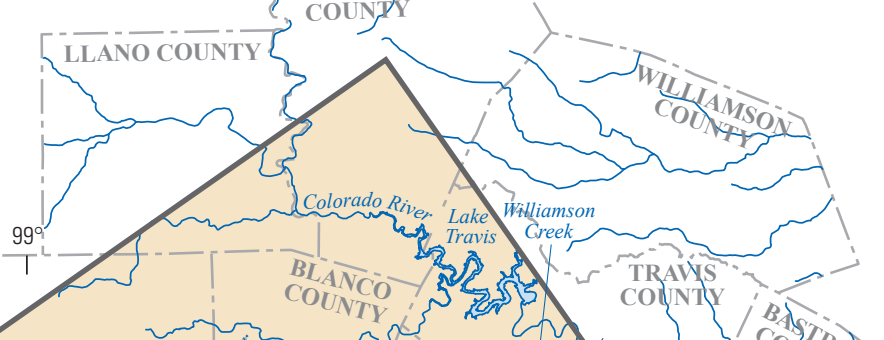

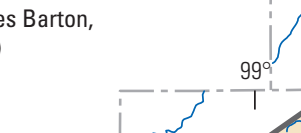
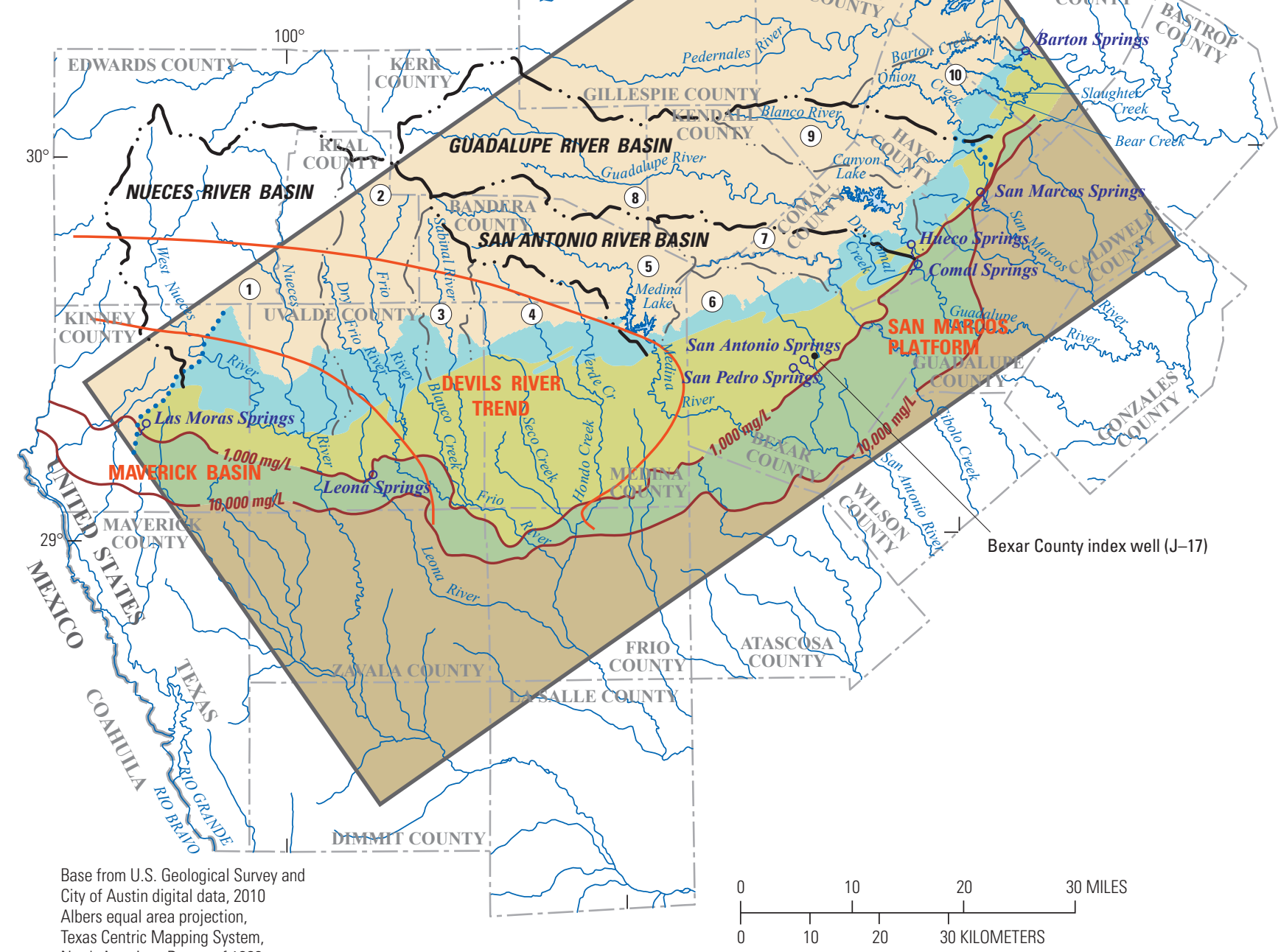

Texas Centric Mapping System, North American Datum of 1983

EXPLANATION

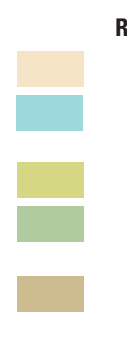

Regional-scale model area

Catchment area

Recharge zone (outcrop) of the Edwards aquifer (modified from Puente, 1978)

Freshwater zone of the Edwards aquifer

Brackish-water (freshwater/saline water) transition zone of the Edwards aquifer

Saline zone

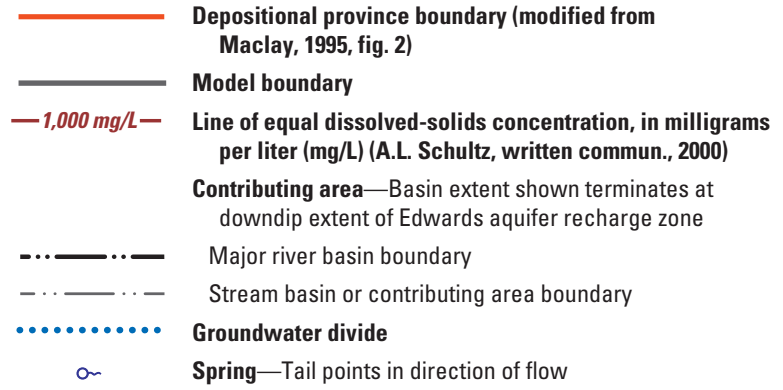

epositional province boundary (modified from

Model boundary per liter (mg/L) (A.L. Schultz, written commun., 2000)

ontributing area-Basin extent shown terminates at

Stream basin or contributing area boundary

Spring-Tail points in direction of flow

Figure 2. Recharge, freshwater, brackish-water transition, and saline zones of the Edwards aquifer, San Antonio region, Texas (modified from Lindgren and others, 2011, fig. 2). 


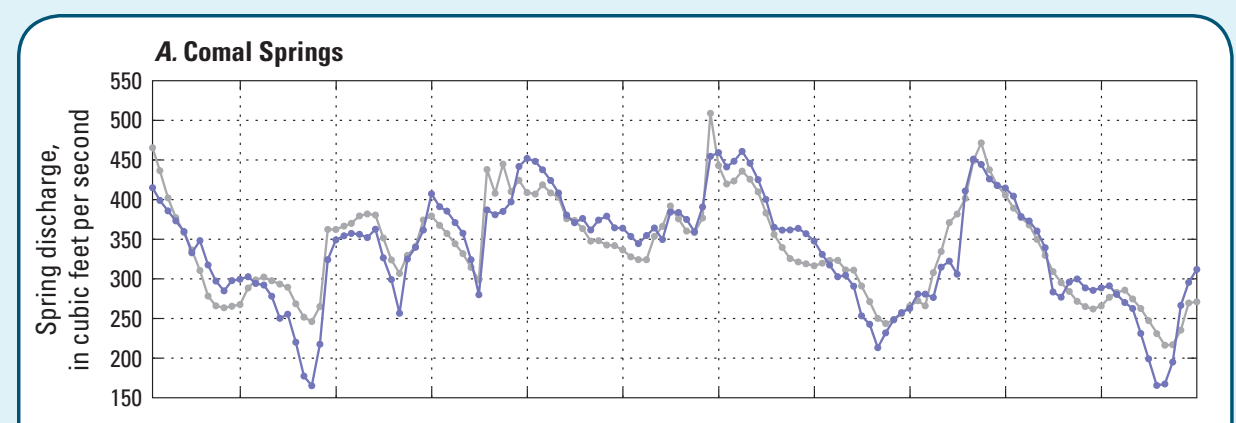

Recharge is the driving force of groundwater flow within the Edwards aquifer but is known to have substantial spatial and temporal uncertainty. Results from the uncertainty analysis indicate that little is learned about recharge by history matching; recharge parameters still remain highly uncertain (fig. $4 B$ ).

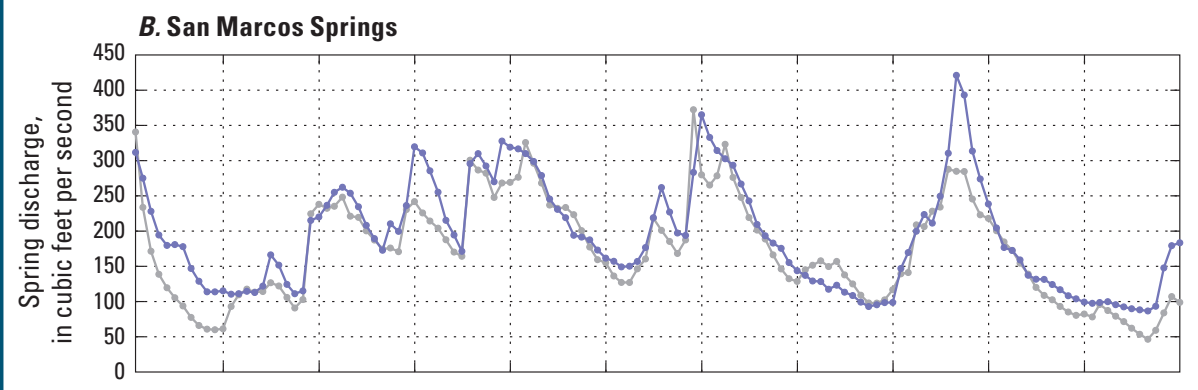

\section{What does uncertainty analysis tell us about the reliability of the model in making a prediction, such as a repeat of drought-of-record rainfall (1950-56)?}

The predictive model in this assessment simulated a hypothetical recurrence of 1950-56 recharge conditions and higher-thanaverage recent groundwater withdrawal rates to provide insight into the potential effects of these conditions on predictions of dissolvedsolids concentration changes at production wells near the transition-zone interface (fig. 5), discharges at Comal and San Marcos Springs, and groundwater levels at well J-17. Uncertainty analysis was also used to quantify the uncertainty of the predictions made with the model, similar to the uncertainty analysis applied to the model inputs. Predictive uncertainty can be thought of as an indicator of the reliability of the model to make a given prediction of aquifer response. The results of the predictive uncertainty analysis focused on the right tail of the Gaussian distribution (upper 95 percent credible interval) for each of the 25 dissolved-solids concentrationchange predictions to represent the expected maximum concentration change.

Results from the predictive uncertainty analyses indicate that a minimal increase in

Linear-based uncertainty analysis was applied to assess the uncertainty of model inputs, such as hydraulic properties and recharge, collectively referred to as "parameters." Prior parameter uncertainty (prior to model calibration) was compared to posterior parameter uncertainty (after model calibration) to determine what was learned about parameters through the history-matching process. Parameter uncertainty is visualized through use of normal, or Gaussian, distributions. Prior parameter uncertainty for different parameter types (such as horizontal hydraulic conductivity, fig. $4 A$ ) is represented as a dashed distribution. Posterior parameter uncertainty for individual parameters within each group is represented as a shaded distribution. Reductions in widths of distributions or increases in the height of distributions, when compared to the dashed distribution of the prior, indicate a reduction in uncertainty (or increase in knowledge) about that parameter through history matching. Many hydraulic properties of the Edwards aquifer remain highly uncertain, even after the model has been history matched (calibrated) to real-world data. dissolved-solids concentration (figs. 5 and 6 ) is expected at these locations during the 7-year predictive period. The uncertainty analysis also indicates that the model is reliable at making this prediction because the model inputs that control these predictions are well informed by the calibration dataset, causing the posterior uncertainty to be greatly reduced (blue bars in fig. 6) when compared to the prior uncertainty (gray bars in fig. 6).

Predictive uncertainty results for total spring flows at Comal and San Marcos Springs during the 7-year period, as well as the results for water-level predictions at well J-17, were substantially different than the results for dissolved-solids concentrations changes at the production wells. The upper bounds of the 95-percent credible intervals for spring flow at Comal and San Marcos Springs and water levels at well J-17 were 10 times larger than the prediction from the calibrated model, which implies that (1) the predictions of spring flows made with this model are not reliable and (2) model inputs that control these predictions are not well informed by the calibration dataset, even though the history-matching effort yielded model inputs that accurately reproduced spring flows and water levels at these locations during 


\section{$\boldsymbol{A}$}

Horizontal hydraulic conductivity

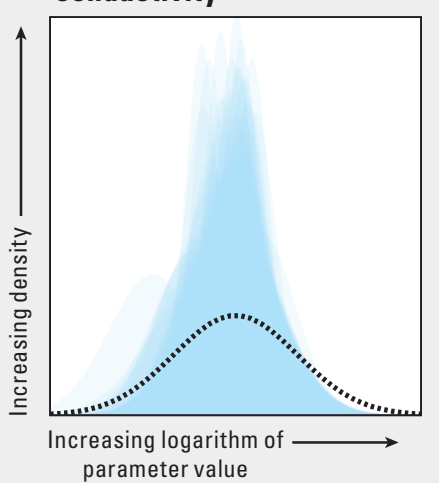

Annual recharge

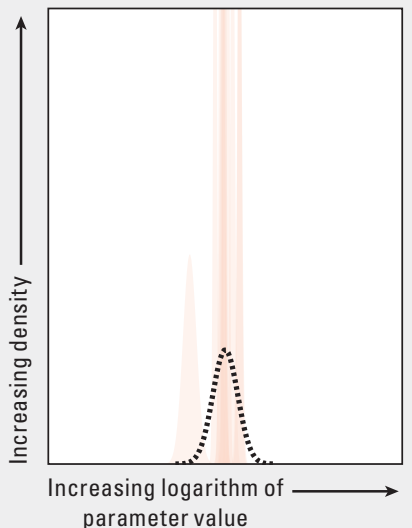

Recharge (drier months)

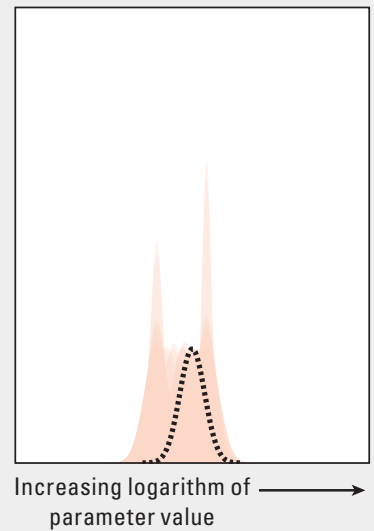

Recharge (wetter months)

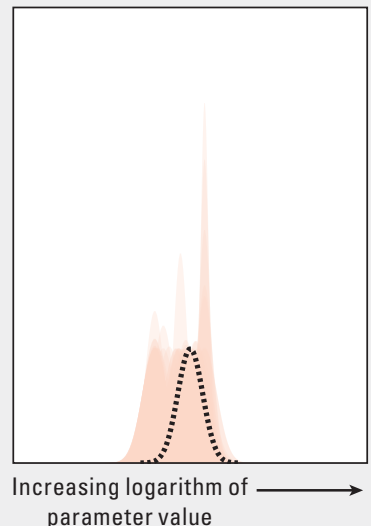

EXPLANATION

Posterior parameter uncertainty distribution for each parameter within the group-The intensity of the shaded area reflects the overlapping of distributions

Upper part of the Edwards Aquifer
Recharge Zone
Prior parameter uncertainty distribution-Uniform for all parameters in this group

Figure 4. Prior (dashed) versus posterior (shaded) plots describing parameters of $A$, horizontal hydraulic conductivity for the upper part of the Edwards aquifer and $B$, annual recharge, drier-month recharge, and wetter-month recharge. The prior plots describe the uncertainty of the parameters before history matching to real-world data, and the posterior plots describe the uncertainty of the parameters after history matching. Prior and posterior plots for many more parameters can be found in Brakefield and others (2015).

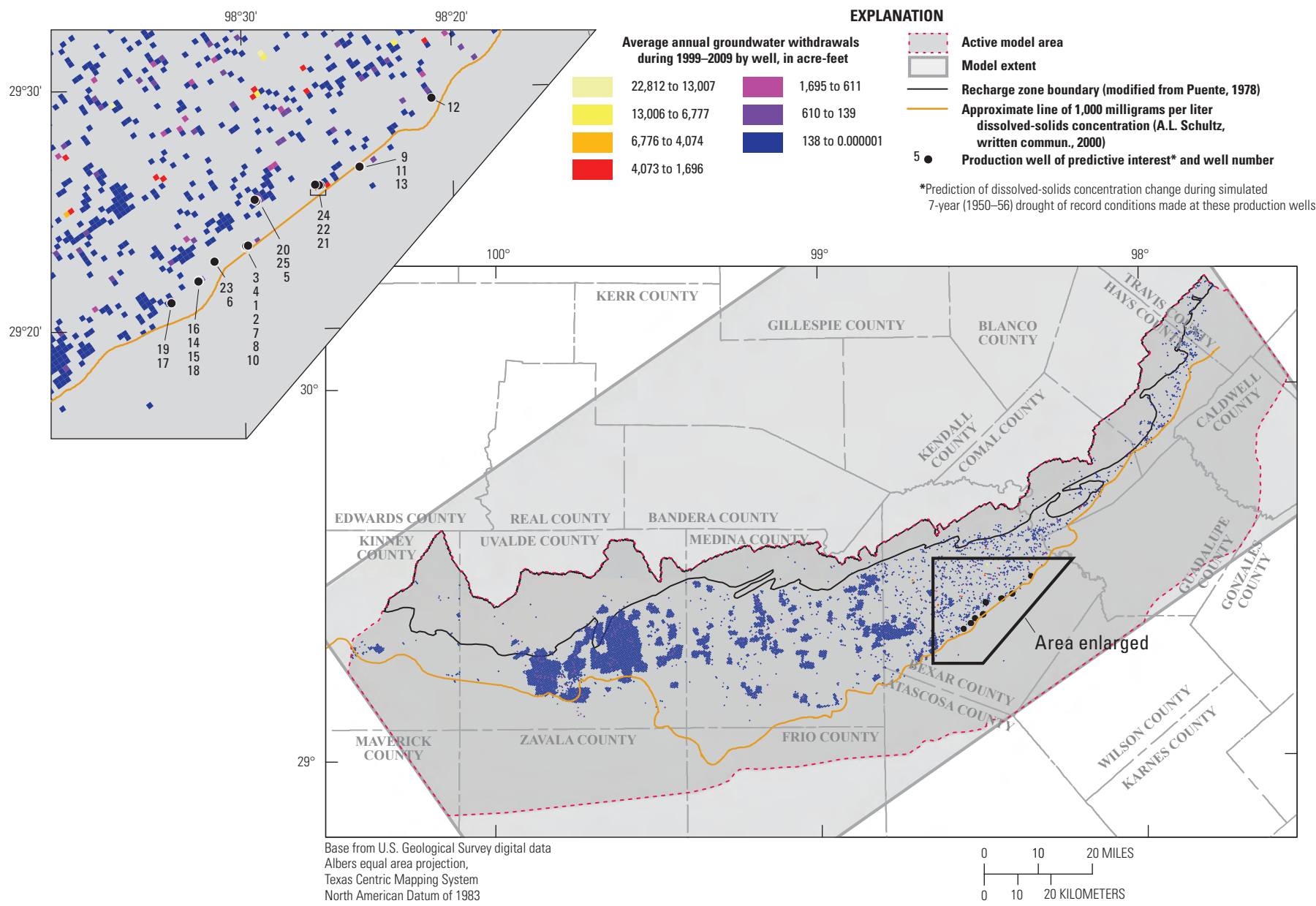

Figure 5. Average annual groundwater withdrawals during 1999-2009, and the production wells of predictive interest near the brackish-water transition zone, San Antonio region, Texas. 


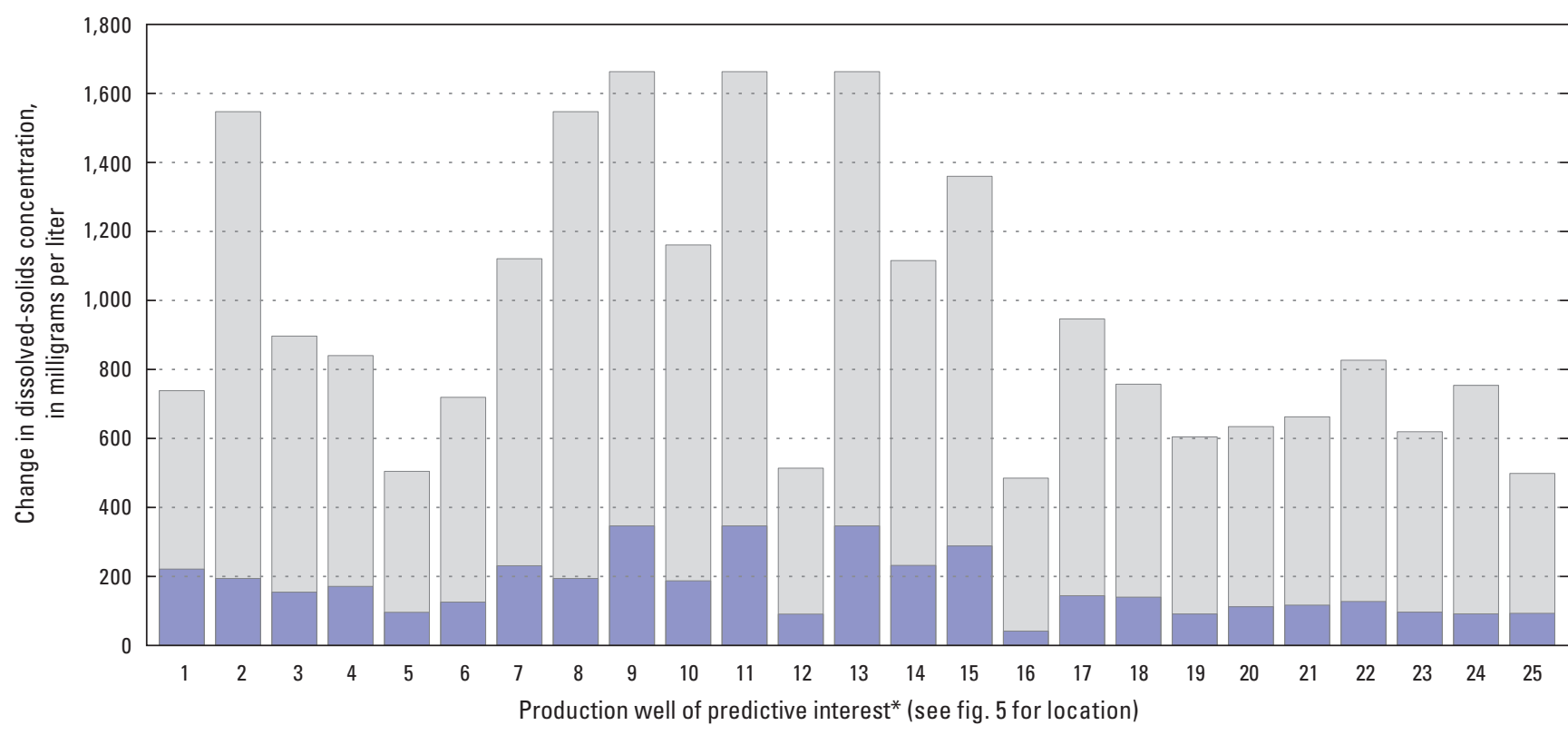

*Prediction of dissolved-solids concentration change during simulated 7-year (1950-56) drought of record conditions made at these production wells

\section{EXPLANATION}

Upper bound of 95 percent credible interval-Change during the $1950-56$ predictive model period

Prior (before history matching) uncertainty of prediction

Posterior (after history matching) uncertainty of prediction

Figure 6. Change in dissolved-solids concentrations at production wells during the 7-year period (1950-56). Gray bars come from the prior distribution (before history matching), and blue bars come from the posterior distribution (after history matching).

the history-matching period. This large uncertainty is likely attributable to the cumulative effect of upgradient conditions on flows at Comal and San Marcos Springs and water levels at well $\mathrm{J}-17$. The large contributing area for these aquifer integration points includes many uncertain aquifer properties. These uncertainties, when combined with recharge uncertainty, result in reduced reliability to predict these quantities of interest.

\section{This fact sheet is based on the following report:}

Brakefield, L.K., White, J.T., Houston, N.A., and Thomas, J.V., 2015, Updated numerical model with uncertainty assessment of 1950-56 drought conditions on brackish-water movement within the Edwards aquifer, San Antonio, Texas: U.S. Geological Survey Scientific Investigations Report 20155081, 54 p., http://dx.doi.org/10.3133/sir20155081.

\section{References Cited}

Lindgren, R.J., 2006, Diffuse-flow conceptualization and simulation of the Edwards aquifer, San Antonio region, Texas: U.S. Geological Survey Scientific Investigations Report 2006-5319, 48 p.

Lindgren, R.J., Dutton, A.R., Hovorka, S.D., Worthington, S.R.H., and Painter, Scott, 2004, Conceptualization and simulation of the Edwards aquifer, San Antonio region, Texas: U.S. Geological Survey Scientific Investigations Report 2004-5277, 143 p.

Lindgren, R.J., Houston, N.A., Musgrove, M., Fahlquist, L.S., and Kauffman, L.J., 2011, Simulations of groundwater flow and particle-tracking analysis in the zone of contribution to a public-supply well in San Antonio, Texas: U.S. Geological Survey Scientific Investigations Report 2011-5149, 93 p.
Lozo, F.E., Jr., and Smith, C.I., 1964, Revision of Comanche Cretaceous stratigraphic nomenclature, southern Edwards Plateau, southwest Texas: Gulf Coast Association of Geological Societies Transactions, v. 14, p. 285-306.

Maclay, R.W., 1995, Geology and hydrology of the Edwards aquifer in the San Antonio area, Texas: U.S. Geological Survey Water-Resources Investigation Report 95-4186, $64 \mathrm{p}$.

Maclay, R.W., and Small, T.A., 1984, Carbonate geology and hydrology of the Edwards aquifer in the San Antonio area, Texas: U.S. Geological Survey Open-File Report 83-537, 72 p.

Puente, Celso, 1978, Method of estimating natural recharge to the Edwards aquifer in the San Antonio area, Texas: U.S. Geological Survey WaterResources Investigations Report 78-10, 34 p.

Rose, P.R., 1972, Edwards Group, surface and subsurface, central Texas: Austin, The University of Texas, Bureau of Economic Geology Report of Investigations 74, $198 \mathrm{p}$

\section{By Linzy K. Foster and Jeremy T. White}

\section{For additional information, please contact:}

Director, Texas Water Science Center

U.S. Geological Survey

1505 Ferguson Lane

Austin, Texas 78754-4501

http://tx.usgs.gov

Publishing support provided by Lafayette Publishing Service Center
ISSN 2327-6916 (print) ISSN 2327-6932 (online) http://dx.doi.org/10.3133/fs20163002 